\title{
LA CONCIENCIA DESGRACIADA HACIA EL REENCUENTRO DEL AMOR: HEGEL Y ROSENZWEIG
}

\author{
Shirly CATZ \\ doi: 10.11144/Javeriana.uph36-73.cahr
}

\section{RESUMEN}

La Estrella de la Redención se postula como una crítica a Hegel y su lógica de la Aufhebung, pero en esta obra Rosenzweig no niega la verdad del sistema hegeliano, sino su absolutización. Desde ese punto de vista, Rosenzweig retoma "otro" Hegel: el de sus Escritos de juventud, atendiendo a su concepción del amor, y el de la Fenomenología del espíritu, en una búsqueda de sistema ligada a la experiencia. Desde un Hegel particular, aunque más allá de él, Rosenzweig construye una filosofía relacional, donde los elementos no se superan sino que conviven entre sí. Analizaremos la fractura de la Totalidad en la triada Dios-Hombre-Mundo, para estudiar luego su relación efectiva a través del amor, y el vínculo necesario entre judaísmo y cristianismo como modo de anticipar la Redención; vínculo desde el cual Rosenzweig sostiene, en contra en este punto de Hegel, que ambas religiones comparten un contenido común, en una relación simbolizada por la letra "y".

Palabras clave: Rosenzweig; Hegel; judaísmo; cristianismo; amor

Universidad de Buenos Aires; Conicet, Buenos Aires, Argentina.

Correo electrónico: shirlycatz@hotmail.com

Para citar este artículo: Catz, S. (2019). La conciencia desgraciada hacia el reencuentro del amor:

Hegel y Rosenzweig. Universitas Philosophica, 36(73), 17-38. ISSN 0120-5323, ISSN en línea

2346-2426. doi: 10.11144/Javeriana.uph36-73.cahr 


\title{
THE UNHAPPY CONSCIOUSNESS TOWARDS THE REUNION OF LOVE: HEGEL AND ROSENZWEIG
}

\begin{abstract}
The Star of Redemption is proposed as a criticism of Hegel's thought and its logic of the Aufhebung, but Rosenzweig does not deny the truth of Hegel's system, only the idea that it is absolute. From this point of view, Rosenzweig takes up "another" Hegel: that of his early writings-from which he draws Hegel's conception of love-and that of The Phenomenology of Spirit - in which he searches for a system that is linked to experience. Based on these particular aspects of Hegel's philosophy, and moving beyond them, Rosenzweig builds a relational philosophy, whose elements are not sublated, but coexist with each other. We will analyze the fracture of Totality in the triad God-Mad-World to study their effective relationship through love, and the necessary link between Judaism and Christianity as a way of aniticipating Redemption. Having this link in mind, and against Hegel's conception, Rosenzweig maintains that both religions share a common content, and that their relation is symbolized by the word "and".
\end{abstract}

Keywords: Rosenzweig; Hegel; Judaism; Christianity; love 


\section{La fractura de la Totalidad}

La Estrella DE LA REDENCIÓN de Franz Rosenzweig comienza con una crítica contundente a Hegel que, curiosamente, deviene en una recuperación del joven Hegel, aunque desarrollando consecuencias distintas de las que este último había formulado. Contra el Hegel maduro, Rosenzweig sostiene que la depurada racionalidad que se derivaría de la eliminación de toda exterioridad, de todo presupuesto, no es sino la mayor enfermedad y alucinación de la filosofía. El neues Denken rosenzweiguiano pretende sustituir las categorías del viejo pensamiento -la filosofía que va "de Jonia a Jena" y su canto monocorde del Uno/Todo y del Todo/Unopor las del judeocristianismo, opuestas a la idea de totalidad clausurada sobre sí. Sin embargo, como el mismo método que Rosenzweig postula, su crítica a Hegel no consiste en una completa negación de su teoría, sino que deviene en una suerte de "pensamiento en capas" siempre en correlación, donde a su formación hegeliana se le agregan, por ejemplo, sus lecturas de Kierkegaard, la influencia de su maestro Hermann Cohen y, de manera fundamental, la filosofía de Schelling (Mosès, 1982).

Una de las mayores novedades de Rosenzweig (1976, p. 221) contra la lógica hegeliana sería el hecho de incluir la temporalidad en el pensamiento, "filosofar en forma de calendario" contra el "calendario puro" donde los idealistas establecen su lógica. Se trata de una manera de proceder que, curiosamente, Rosenzweig le reconoce al Hegel de la Fenomenología, puesto que allí Hegel presenta los distintos momentos de la conciencia a través de la experiencia. Por eso, estamos de acuerdo con Görtz (1984) en resaltar la estructura hegeliana de La Estrella, aunque admitimos, con Pollock (2014), tanto la influencia de Schelling como la de Hegel en la filosofía rosenzweiguiana, en el sentido de que ambos apuntan a la idea de un "sistema" de filosofía.

Desde este marco es comprensible que Rosenzweig se interese por la Fenomenología del espiritu como un caso particular dentro de la filosofía hegeliana, pues la misma combina un sistema con la experiencia de ese sistema. Como sostiene Rosenzweig en Hegel y el Estado (2007b), Hegel nunca se manifestó más alejado de su absolutismo del Estado que en esta obra. Más que afirmar o negar esta 
interpretación ${ }^{1}$, lo que nos interesa es este lugar privilegiado de la Fenomenología y su cercanía con la filosofía de Rosenzweig. Según Navarrete (2016): "Rosenzweig y Hegel están de acuerdo en que el problema de la era moderna es la división, o que enfrentan la misma pregunta, desde desarrollos espirituales muy similares" (p. 2$)^{2}$. Esto significa que, aunque Rosenzweig (2007a) le declare a Meinecke en una carta de 1920, por ejemplo, que "el autor de La Estrella es de un calibre completamente distinto del de Hegel y el Estado" (p. 83), las similitudes no dejan de estar presentes. De ese modo, Rosenzweig no solo dejaría atrás a Hegel, sino que apuntaría a su "renovación dialéctica" (Görtz, 1984, p. 138) centrándose en la idea de su apertura permanente; por eso su verdadero foco crítico no sería el espíritu, sino, en verdad, el misticismo (Görtz, 1984, p. 327).

Desde ese punto de vista, consideramos que tanto La Estrella de la Redención como la Fenomenología del espiritu pueden leerse bajo la pretensión "fenomenológica" de

atenerse a lo que se da, tal como se da, y dentro de los límites de lo que se da [...] sin hacer referencia a fenómenos previamente dados, sino apuntando a que se haga manifiesto lo que, hasta el momento, ha permanecido oculto en la oscuridad de lo impensado (Fink, 2011, p. 19).

Se trata, entonces, en los dos casos, de "abordar la exposición del saber tal y como se manifiesta" (Hegel, 2000, p. 54), y desde allí emprender un viaje tumultuoso hacia la "salida de la caverna": la recompensa de un camino muy sinuoso y de esfuerzos y desvelos no menos arduos y diversos donde "reconoceremos la historia de la cultura proyectada como un contorno de sombras” (Hegel, 2000, p. 21).

La diferencia entre las dos obras consiste en que, mientras que para Hegel se trata de analizar los estados purificadores que nos conducen desde el saber empírico hasta el filosófico, desde la certeza sensible hasta el saber absoluto, como estaciones prescritas por su propia naturaleza, para Rosenzweig se trata, en

1 Para su crítica, véase Hyppolite, 1974, p. 205.

2 „Rosenzweig und Hegel darin übereinstimmen, dass das Problem der Neuzeit inder Entzweiung besteht bzw. dass sie der gleichen Frage entgegentraten, und zwar aus sehr ähnlichen geistigen Entwicklungen." Tanto esta como las demás traducciones de las citas tomadas de textos no disponibles en español son propias. 
cambio, de reconducirnos hacia una filosofía del mundo (Welt). En ese sentido La Estrella de la Redención podría leerse como una "salida de la caverna invertida" - "Ich bleibe also Jude", postula Rosenzweig en su famosa carta a Ehrenberg (1976, p. 133), contra la idea del camino ascendente- donde la historia no es teodicea, pues “¿para qué necesitaríamos un Dios si la historia fuera divina?” (Rosenzweig, 1976, pp. 112-113)³ y en todo caso: “¿una historia de lo Absoluto sigue siendo una historia?” (Görtz, 1984, p. 326)4.

Por otra parte, ambas obras parten del estudio de la conciencia a través de "configuraciones", en tanto "figuras" específicas de la conciencia. De hecho, la primera figura analizada por Rosenzweig es justamente la del propio Hegel -luego lo serán las de Kierkegaard, Schopenhauer, Nietzsche, el mundo griego (Platón, Aristóteles y los sofistas), India y China, junto con el estudio de creaciones literarias y artísticas, como hace también Hegel-. La Estrella de la Redención puede leerse, entonces, como una continuación de la novela de formación (Bildungsroman) hegeliana, aunque mostrando, esta vez, que la superación del pensamiento hegeliano no es tanto novedad como retorno hacia alguno de los momentos que el espíritu (Geist) había creído superados para eliminar, en todo caso, la idea misma de "superación", en pos de una cierta "conjunción" dialógica.

El primer momento de la Fenomenología es, como sabemos, el de la "certeza sensible" en tanto saber inmediato o "de lo que es". Ecos parmenídeos y rapidísima inversión hegeliana: dicha conciencia cree poseer el conocimiento más rico, el más verdadero y el más determinado, pero precisamente allí donde se imagina ser el más rico, este conocimiento es el más pobre, el más falso precisamente cuando se imagina ser el más verdadero, y sobre todo, el más indeterminado precisamente cuando se imagina que es el más determinado. No es una observación hecha desde afuera sino que, para Hegel, la certeza sensible se da a sí misma como la más abstracta y pobre. Discurso silencioso, casi mudo, que a lo sumo dice "es": el ser inmóvil e inmediato.

3 "Wir sehen Gott in jedem ethischen Geschehen, aber nicht in dem fertigen Ganzen, in der Geschichte; - denn wozu brauchten wir einen Gott, wenn die Geschichte göttlich wäre, wenn alle Tat, in dieses Becken fießend, ohne weiteres göttlich, gerechtfertigt würde."

4 „(...) ob den eine Geschichte des Absoluten überhaupt noch eine Geschichte sei." 
La certeza sensible sabe solo el ser al rechazar toda mediación; la riqueza del saber sensible pertenece, afirma Hegel, a la percepción. La certeza sensible piensa que lo esencial es el objeto, pero llega a la conclusión de que lo único que puede decir es que "el Ser es". A una velocidad inusitada, la plétora fenoménica parece haberse escurrido entre nuestras manos, mezclada, en realidad, con el proceso de autoconciencia que lo determina. La dialéctica ha hecho de la suyas y ha puesto en evidencia que $\mathrm{Ser}=\mathrm{Nad}$.

¿Pero y si la nada no es necesariamente una? Rosenzweig muestra, al comienzo de La Estrella, que ni siquiera la "Nada" es una, sino plural, alejándose en este punto del esquema hegeliano. Se trata de tres tipos de nadas del saber: Mundo, Dios y Hombre. No tenemos conocimiento acerca de estas tres nadas, pero tenemos "creencia", la irrenunciable certidumbre de la realidad de nuestra propia existencia, del mundo y de Dios, anterior a todo pensamiento. "Facticidad suprarracional”, experiencias que no podemos evitar tener, y que suponen la destrucción del todo idealista, desde que intuimos la imposibilidad de reducir cada una de estas nadas del saber a la otras.

Desde este momento, la nada ya no quiere decir revelación esencial del ser puro, como quiso decir para el gran heredero de los dos mil años de historia de la filosofía, sino que de lo que se trata es de "la constante derivación de un algo -y nunca más que un algo, un algo cualquiera- a partir de la nada, pero jamás a partir de la nada vacía y universal" (Rosenzweig, 1997, p. 59).

La misma pretensión fenomenológica que llevó a Hegel a caracterizar la certeza sensible como lo más abstracto e indeterminado lleva a Rosenzweig a responder, en cambio, que lo primero que se da son tres objetos irracionales, en el modo de la facticidad, y dentro de los límites de la idea. Se trata de nadas epistemológicas, pero no de nadas experienciales, por lo que de ningún modo son nadas absolutas.

Cada una de estas creencias preoriginales es, a la vez, síntesis de una afirmación y de una negación primordial. Nuestra intuición de la facticidad se traduce, antes de todo tipo de conciencia, por un doble movimiento de afirmación y de negación:

1. Afirmación de la no nada (la no nada es): afirmación de una posición (morador). 
2. Negación de la nada (la nada no es): categoría de la pura diferencia, de la determinación infinita (fugitivo).

De estas vías se conforman las ecuaciones generales de los metaobjetos como “ $y=x$, que no marcan una identidad, sino el modo en que se aplica $y$ a $x$, o el modo en que se configuran ambos momentos. Este movimiento, evidentemente, no es dialéctico, ni se da al modo de una síntesis clausurante. Si bien se pone "entre paréntesis" la realidad efectiva del mundo - por lo que el hecho de que la idea que experimentamos se corresponda, o no, con un Dios efectivamente así, no lo puede determinar el pensamiento- no se puede dudar de estas vivencias de la conciencia, de estas facticidades que se dan en la experiencia como ideas.

Para el caso de la idea de "Dios", su "así, por la vía de la afirmación, se experimenta como infinita posición de ser, como "infinita facticidad": al experimentar la idea de Dios, experimentamos que su ser es la infinitud. Por la vía de la negación, el acto por el cual Dios dice "no" a su nada, notamos que la idea de Dios no puede ser sino un acto de libertad infinita, que realiza $(=)$ el ser infinito, apuntando a un ser infinito. Queda así conformada la ecuación "A = A", donde "A = ..." simboliza la libertad divina, "A" la esencia infinita, y el " = " la "vitalidad de Dios". La idea de un ser infinito no puede sino pensarse en relación con la libertad infinita, esto es, si pensamos a Dios (y de hecho lo pensamos), no podemos sino pensarlo como algo infinito que, a su vez, todo lo puede. Si no lo pudiera todo, aunque pudiera mucho, no sería la idea de Dios, sino a lo sumo un semidiós o un superhombre. Y si pensáramos que "Dios es todo pero no puede nada”, la idea ya no se correspondería con Dios, sino con el mundo. Por lo que la idea de Dios no puede ser sino la idea de un ser infinito, ligado a una libertad infinita. Esto, repetimos, nada dice acerca de si Dios efectivamente existe o no: pues de esta idea de Dios no es posible, como pretendía el argumento ontológico tradicional, deducir su existencia.

Para el caso del "mundo", la vía de la afirmación expresa el mundo como aquello que es siempre y por doquier, ligado a un lógos sistemático; y la vía de la negación, la plétora de fenómenos que acaecen, como "dones siempre nuevos". Revolución copernicana que determina, en este caso, la prioridad del ser por sobre el pensar: la pasividad de la forma, y la actividad del contenido. De allí que la dirección $(=)$ provenga del lógos, que necesita aplicarse, mientras que lo particular (B) carece de dirección, limitándose a ser. La ecuación conformada sería 
entonces: "B $=A$ ", donde " $B$ " representaría el fenómeno particular y “ $\ldots=A$ " simbolizaría la ley universal y su necesidad de "aplicarse a”. Mientras que para el idealismo el fenómeno es síntesis del pensamiento y lo dado, para Rosenzweig la síntesis es ya inmanente al mundo, donándose espontáneamente como unidad de lo sensible y lo inteligible. El fenómeno es lo que está siempre acaeciendo. El fenómeno es, así, lo siempre nuevo, la maravilla, y la "crux" del idealismo, que tuvo que falsificarlo, adormecer su hirviente plenitud y domesticarlo hasta hacer de él el caos muerto de lo dado. El punto, para Rosenzweig, es no dejar de lado la vida, pues como nos dice Gordon (2003): "si bien 'vida' es la última palabra de su libro, también es, en cierto sentido, la primera” (p. 175)5.

Para el caso del "hombre", por último, su afirmación es su propio ser finito, y su negación, su querer infinito. Libertad tan infinita en su querer, como la de Dios en su poder. Libertad que se dirige a ser su propio ser, como ser suyo, conformando la ecuación " $\mathrm{B}=\mathrm{B}$ ", donde “ $\mathrm{B}=$..." simboliza su ser sí mismo, y " $\mathrm{B}$ ”, su libertad, en un obstinado "querer hacerse a sí mismo".

\section{La conciencia desgraciada y el amor}

Al análisis de los metaobjetos “Dios", “Hombre” y "Mundo" que establece Rosenzweig le es aplicable, en principio, la crítica hegeliana a la conciencia desgraciada, la moralidad y la religión. En su "triplicidad irracional", caería dentro de ciertas críticas de Hegel a la filosofía kantiana (aunque aquí se trate de objetos irracionales) cuando establece, por ejemplo, que no es posible "considerar como algo científico la triplicidad kantiana, redescubierta solamente por el instinto, todavía muerta, todavía aconceptual, elevada a su significación absoluta" (Hegel, 2000, p. 33). Hegel arremete continuamente contra la conciencia basada en la intuición y el conocimiento directo, dado que ello implicaría exigir para la exposición de la filosofía "más bien lo contrario a la forma del concepto. Se pretende que lo absoluto sea, no concebido, sino sentido e intuido” (Hegel, 2000, p. 10).

La "conciencia desgraciada" es, como sabemos, la gran protagonista de la $\mathrm{Fe}$ nomenología. En sus trabajos de juventud, Hegel (1978) ya había reflexionado

"If life is the final word of the book, it is also in a certain sense the first." 
acerca de la misma, estableciendo una contraposición entre el pueblo griego, que consideraba como el más feliz, y el pueblo judío, que se le aparecía como el más desgraciado, refiriéndose a

la triste condición de la nación judía, de una nación que derivaba su legislación de la suprema sabiduría, pero cuyo espíritu estaba oprimido entonces por toda una carga de mandamientos estatutarios, que prescribían pedantemente una regla para todo acto indiferente de la vida diaria, dando a toda la nación el aspecto de una orden monacal, de un pueblo que ha reglamentado y reducido en fórmulas muertas lo más sagrado, el servicio de Dios y de la virtud, sin dejar a su espíritu (ya profundamente mortificado y amargado por la sujeción de su Estado bajo un poder extranjero) otra salida que el orgullo por esta obediencia de esclavos a leyes que no se dieron ellos mismos (p. 74).

El pueblo judío (que no será nombrado en la Fenomenología, pero cuya referencia es evidente) representa la primera reflexión total de la conciencia fuera de la vida, tal y como ocurre con la figura de Abraham, quien corta con todos los vínculos naturales para seguir el llamado divino. Abraham abandona, para Hegel, la relación con la naturaleza: no cultiva la tierra ni la adula, era un extraño en la tierra, y por eso, "Abraham no quería amar. No quería ser libre a través del amor” (Hegel, 1978, p. 226). En su desvinculación, Abraham desgarra los vínculos de amor y convivencia. Tragedia shakespeariana, como el Macbeth, tragedia sin reconciliación posible. El judaísmo es aquella religión que puede ser terriblemente sublime, apunta Hegel, pero nunca bellamente humana.

El momento de la Revelación en Rosenzweig repite ese esquema de ruptura radical, a partir del llamado divino a Adán en el relato del Génesis. Contra la crítica hegeliana al judaísmo, sin embargo, el primer mandamiento, para Rosenzweig, es el del amor, primero en la relación con Dios, pero inmediatamente apuntando hacia el mundo. De ese modo, como una suerte de "caverna platónica invertida" (Mosès, 1982, p. 77), el segundo libro de La Estrella nos lleva más cerca de un mundo verdadero pero que, curiosamente, es más concreto. Dios mismo, cuando lo queremos comprender, se oculta; el hombre se cierra, el mundo se vuelve enigma visible. Ellos se abren solo en sus relaciones, como en la serie CreaciónRevelación-Redención. 
El hombre de la "caverna platónica" escucha, de pronto, una primera voz. La primera relación es pregunta. La primera pregunta es un dónde. Dónde estás, le pregunta Dios a Adán: es el traspaso del misterio al milagro. El hombre rompe la imaginaria corteza que lo tenía apresado en la eternidad de la lógica: de fantasma, el hombre se ha vuelto cuerpo. Para descubrir, así, la realidad efectiva. Y de ese modo, el tiempo. Me experimento, entonces, como alma amada por un poder que a cada momento me invita a ser: "se descubre el Yo en el momento en que afirma la existencia del tú preguntando por el dónde del tư" (Rosenzweig, 1997, p. 221).

Sin embargo, habrá un primer momento en el que el hombre se seguirá ocultando, permaneciendo como sí mismo mudo. A la pregunta divina por el tú responderá, entonces, con un "él/ella/ello". "Ha sido la serpiente", responde, queriendo permanecer como mero fragmento del mundo. El sí mismo quiere ser conjurado con un hechizo más poderoso que la mera pregunta por el tú. Será, pues, necesario algo más fuerte para despertar al hombre a su unicidad: el llamado de Dios por el nombre propio. Allí se corta cualquier escape a la objetivación, cuando en lugar de un concepto universal, lo llamado resulta ser lo incapaz de huida: el nombre propio. Frente a él, el hombre ya no podrá señalar a otros, sino que, todo él abierto, todo él extendido, todo él dispuesto, todo él oídos, responderá: "aquí estoy”.

Notamos que este esquema es, en su base, similar al "proceso de la autoconciencia" hegeliana; de hecho, así había interpretado Hegel la religión judía: como una relación entre un Dios que es todo, en tanto amo, y hombres que son siervos alienados. En primer lugar, tanto en Hegel como en Rosenzweig este momento de la autoconciencia se constituye en un verdadero "salto". Con la autoconciencia entramos, pues, en el "reino de la verdad" (Hegel, 2000, p. 117), como plantea Fink (2011):

Pero ¿qué significa entonces su salto de la conciencia a la autoconciencia? Lo que, ante todo, no significa, es que la pregunta por el ser alcance la paz, que desemboque en la ausencia de cuestiones, en un conocimiento seguro de lo que es el ser. No significa que haya un sector del ente que venga dogmáticamente dado como el único ser verdadero y propio. También tras el paso a la autoconciencia, Hegel sigue profundizando en la pregunta de todas las preguntas. El que el paso se lleve a cabo como salto no viene dado porque Hegel 
realice un intento de salvación y que, en el general naufragio del ente, que se ha vuelto cuestionable, se aferre a la tabla segura del sujeto indudable. El salto es, exclusivamente, el paso de lo finito a lo infinito (p. 182).

Hegel podría criticar, sin duda, que el reconocimiento en Rosenzweig no se conforma a partir del otro hombre, de otra autoconciencia igual a la mía, sino a partir de lo que está más allá de mí, pero para Rosenzweig (1997) la "llamada divina" no es sino el símbolo de cualquier procedimiento dialógico, esto es, de cualquier proceso de reconocimiento y autoconciencia: "el Yo auténtico, no autocomprensible, enfático y subrayado, se pronuncia por primera vez al descubrir el Tú. En efecto, también Dios pregunta dónde está el Tú” (p. 216). Para Hegel, a su vez, la autoconciencia es la reflexión, que es esencialmente el retorno desde el ser otro, desde el ser del mundo sensible y percibido.

En la Fenomenología, sin embargo, Hegel le ha restado importancia al tema del amor, tan característico de sus primeros trabajos (cuestión que no está ausente, pero que ha perdido protagonismo), destacando, en cambio, la lucha de las autoconciencias como dominación, y más adelante, la defensa de la guerra como aquella que impide que los sistemas particulares se separen del todo. En la Fenomenología Hegel se referirá al "deseo", pero este deseo es fundamentalmente deseo viril y lucha.

Rosenzweig, en cambio, convierte el amor en el tema central de La Estrella. Toda su obra podría leerse como una respuesta a Hegel y su crítica a Abraham para demostrar de qué manera el pueblo judio puede volver a amar. También puede ser leída como una crítica a la justificación hegeliana de la guerra, tal como esta aparece en la última parte de la Fenomenología. Ya desde la relación entre Dios y el hombre, lo que Rosenzweig destaca es el amor. Para Rosenzweig, de hecho, el hombre es “amado” y Dios “amante”, lo que constituye una gran inversión en relación con las premisas religiosas tradicionales. El hombre se abre a Dios, pero no se humilla ni se pone como inesencial, sino todo lo contrario: oye su nombre propio y se reconoce en esa primera llamada de un Tú que lo interpela. En ese punto, entonces, Rosenzweig parece retomar las reflexiones del joven Hegel, que planteaba que la dualidad de las autoconciencias y su unidad en el elemento de la vida podían presentarse a través de la dialéctica del amor. El amor se aparecía, entonces, como el milagro por medio del cual el dos puede volverse uno, sin suprimir completamente la dualidad: 
Por supuesto que el amor no puede ser mandado. Por supuesto que es algo patológico, que es una inclinación; pero esto no quita nada de su grandeza. No se ve degradado porque su esencia no comporte una dominación sobre algo que le sea ajeno y, lejos de ser por ello algo inferior al deber y al derecho, es su triunfo no señorear por encima de nada, no ser un poder hostil frente al otro. 'El amor ha vencido' no significa lo mismo que 'el deber ha vencido', es decir, que ha subyugado a sus enemigos; significa más bien que ha sobrepasado a la enemistad [...]. Ama a tu prójimo como a ti mismo no significa amarlo tanto como a sí mismo, porque 'amarse a sí mismo' es una expresión sin sentido; significa más bien 'Ámalo en tanto él es tú. El amor es el sentir de una vida igual, ni más poderosa ni más débil (Hegel, 1978, p. 338).

Para Rosenzweig (1997), Dios se dirige al hombre a través de la palabra que le ordena amar y en esta calma dispuesta a la escucha el alma amada experimenta el amor divino, no como propiedad, sino como acontecimiento:

[que] Dios ama no significa que el amor le es propio como una propiedad, como, por ejemplo, el poder de crear. El amor no es la forma fundamental, fija e inmutable de su rostro, sino el gesto fugaz -nunca una mueca seca-, el brillo siempre joven que ilumina los eternos rasgos (p. 209).

El abrirse de Dios al hombre, por medio de un amor que no es propiedad ni del amado ni del amante, se da como algo que surge a cada momento, siempre de nuevo, siempre cada vez.

El peligro es siempre el del misticismo, que Hegel critica por ejemplo en Fichte o Schelling: en sus concepciones de un ser en el misterio, inaccesible -de allí sus dificultades para explicar lo fenoménico: Schelling tuvo que hacerlo con la metáfora de "la caída"; Fichte, a través de la noción de "hiato irracional" que no se explica, sino que acaece-. Pero también al misticismo se enfrenta Rosenzweig. Frente a la llamada divina, el hombre se autopercibe, y corre el riesgo de quedarse encerrado en sí mismo. Por un lado, ha salido de su encierro, y ahora se encuentra expandido y abierto: pero abierto en una sola dirección. Ya no duerme el rígido sueño del sí-mismo, pero solo se ha despertado para Uno. Así que, en realidad, sigue estando ciego y sordo, como lo estaba el sí-mismo. Niega el mundo, lo trata como si no existiera, y por eso el místico se niega a sí mismo como hombre. 
Para Rosenzweig se trata de mostrar, en todo caso, un tipo de relación sin coincidencia. Por eso la relación efectiva se aparece del lado del mundo, como relación milagrosa: La "ruta de la Revelación" muestra que Dios se dirige al hombre a través de la Revelación, y que el hombre debe volverse al Mundo para realizar la Redención. Esta es, como nos dice Pollock (2014), su verdadera conversión y lo que lo alejó definitivamente del marcionismo: la convicción de que el mundo puede ser redimido por la acción humana (sin devenir, por eso, en mera inmanencia). En ese sentido, el "seguir siendo judío" no implicaría un "regreso" al judaísmo, sino una toma de conciencia acerca de la importancia del mundo. Retomaremos esto al relacionar en el tercer apartado la relación entre judaísmo y cristianismo. Su vuelta al judaísmo, adelantamos, a diferencia de lo que plantea Hegel, tendría que ver, no con un pasaje del relativismo a la fe (como plantean los mitos, explica Pollock, en relación con su conversión), sino de la negación marcionita del mundo a la afirmación del mundo en el judaísmo.

De ese modo, la "no coincidencia" entre los elementos no produce una conciencia desgarrada, llorando su nada frente a la ley del Padre, sino que La Estrella de la Redención se aparece como una clara exigencia de volverse al mundo. El verdadero corazón de La Estrella es esta exigencia de no abstraerse del mundo, ni en términos naturales, ni en la relación con el prójimo, al que se vuelve el mandamiento del amor divino, en la forma "ama a tu prójimo como a ti mismo".

Notamos en este punto la gran influencia de su maestro Hermann Cohen, fundamentalmente a través de su concepto de "correlación". A través del mismo, Cohen y Rosenzweig pueden explicar cómo la serie de correlaciones que vinculan a los hombres entre sí realizan una correlación superior entre el hombre y Dios. El conocimiento de Dios no puede separarse de la relación ética interhumana sino que, por el contrario, le es absolutamente esencial. Si la religión queda sumida en una mera relación entre Dios y el Hombre, es simplemente mito. Por eso nunca puede ser, como plantea Hegel, obediencia ciega; debe constituirse en la relación con el Otro: con la viuda, el huérfano, el extranjero. Debe volverse al mundo, cada vez.

Si la conciencia desgraciada se comporta de cara a lo inmutable de tal forma que ello se le aparece como lo esencial, y lo mutable como lo inesencial, creyéndose nada (momento que podemos pensar, como decíamos, en relación con la religión judía, pero también como momento existencial general del hombre), el 
hombre rosenzweigiano se vuelve al mundo, comprendiendo, en cambio, que el mandamiento del "debes amar" contiene, a su vez, el mandamiento: "como Él te ama, así ama tứ. Como en cierto sentido planteaba Hegel, puede entender que el yo es el nosotros y el nosotros, el yo.

El mandamiento de amor no tiene su origen en la voluntad del sujeto, sin ser por eso un acto forzado por Dios. Dios nos llama, nos despierta, a cada instante. El amor al prójimo es una respuesta al amor primero de Dios y es el cumplimiento en el mundo, a cada instante, de ese amor primero. La "ruta de la Revelación" muestra que Dios nos ama primero, y nuestra "correspondencia" a su amor se testimonia en el "amor al prójimo". En la Redención el hombre está orientado al mundo, no en general, sino en un representante en particular: el prójimo. El sí mismo no puede permanecer en el mero éxtasis de sentirse amado por Dios, sino que tiene que exponerse, abandonar el mero "sí" hacia Dios.

En este punto, Hegel ya no hubiera podido criticar el misticismo -pues el alma se ha vuelto al mundo concreto- pero sin duda habría seguido criticando el concepto de "mandamiento" en la filosofía rosenzweigiana. En la sección "La razón legisladora" de la Fenomenología, Hegel establece que, en tanto la autoconciencia se sabe como momento del ser para sí de la sustancia ética, expresa en ella el ser-allí de la ley, de tal modo que la sana razón sabe de un modo inmediato lo que es justo y bueno. $\mathrm{Y} \tan$ inmediatamente como lo sabe, $\tan$ inmediatamente vale para ella y puede decir, también de un modo inmediato: "esto es justo y bueno". Las "leyes éticas inmediatas" hacen afirmaciones del tipo: "cada cual debe decir la verdad". Pero en este deber, enunciado como incondicionado, se debe admitir enseguida una condición: "si sabe la verdad" (Hegel, 2000, pp. 247-248). Por lo tanto, cada cual debe decir la verdad, siempre con arreglo a su conocimiento y a su convicción acerca de ella; pero en ese momento lo universal necesario, lo valedero en sí que esta máxima se proponía enunciar, más bien se invierte, convirtiéndose en algo totalmente contingente.

En efecto, el que se diga la verdad queda sujeto al hecho contingente de que yo la conozca, por lo que la máxima se contradice a sí misma. Al principio, la sana razón debía tener de un modo inmediato la capacidad de decir la verdad, pero ahora se dice que debía saber la verdad, es decir, que no sabe enunciarla de un modo inmediato. 
Otro precepto famoso, explica Hegel (2000, p. 248), es justamente el de "ama a tu prójimo como a ti mismo", precepto dirigido al individuo en relación con otros individuos. El "amor activo" tenderá, entonces, a hacer el bien y evitar el mal. Pero para eso, debe saber lo que es el mal y el bien para él, lo que conlleva o no su bienestar, por lo que debemos amar al prójimo "de un modo inteligente". Pero eso corresponde no al individuo, sino al Estado (Hegel, 2000, p. 249).

Su crítica a la conciencia moral deviene, finalmente, en una crítica a la religión. La conciencia moral se enreda en una contradicción que parte del tener que obrar, y de la determinación de la moralidad, en un segundo momento, como "tarea infinita". Para, finalmente, verse obligado a poner el deber en otra autoconciencia:

La concepción moral del mundo no es, por tanto, de hecho, otra cosa que el desarrollo total de esta contradicción fundamental con arreglo a sus diversos lados; es, para emplear una expresión kantiana aquí donde mejor cuadra, toda una trama de contradicciones carentes de pensamiento. En este desarrollo la conciencia se comporta de tal modo que, fijando un momento, pasa inmediatamente al otro y supera el primero, pero apenas ha establecido este segundo lo deforma de nuevo, y convierte más bien lo contrario en la esencia (Hegel, 2000, p. 360).

La conciencia moral no quiere más que el deber, pero quiere realizarlo. Al actuar, la conciencia moral sufrirá una dolorosa experiencia: tomará conciencia de la independencia del obrar en relación con el deber moral. Por eso tratará de resolver esta contradicción poniendo una conciencia distinta a la efectiva: la de un santo legislador del mundo. Es el traspaso hacia la religión, que nos mostrará los deberes como mandamientos de Dios.

Rosenzweig trata de salvar esta cuestión distinguiendo entre "ley" y "mandamiento", distinción que, como vimos, tiene su origen en el joven Hegel, cuando caracterizaba al amor como "aquello que no se puede mandar". Cuando Hegel analiza el Sermón de la Montaña de Jesús, por ejemplo, explica justamente cómo en el amor desaparece todo pensamiento de deber. No la disolución de las leyes, sino la necesidad de que las mismas se colmen con una justicia distinta, que se puede resumir con un "más": unificación de la inclinación con la ley, por la cual esta pierde su forma de ley. La reconciliación en el amor es una liberación; en vez 
del reconocimiento renovado de la dominación, es la libertad suprema, la superación de la dominación en la restauración de la unidad viviente.

Por eso el amor, lejos de ser por ello algo inferior al deber y al derecho, es su triunfo, porque no expresa ningún deber. Notamos, en este punto, la dialéctica hegeliana en estado naciente, donde el amor no es un universal que se oponga a una particularidad; no es una unidad del concepto, sino unión del espíritu y divinidad. Es solamente a través del amor que puede quebrarse el poder de la objetividad, derrumbando el ámbito del mismo.

El mandamiento manda lo que la ley no puede, porque justamente, "manda amar". Este movimiento es sin dudas paradójico: ¿Cómo puede "mandarse” el amor? "Cierto que el amor no se puede mandar. Ningún tercero puede ordenarlo y forzar a él. No puede ningún tercero, pero sí lo puede Uno" (Rosenzweig, 1997, p. 223). El mandamiento del amor solo puede venir de la boca del amante. Únicamente el amante puede decir: ámame. En su boca el mandamiento del amor no es un mandato ajeno, sino nada más que la propia voz del amor. A diferencia de la ley, es presente y solo sabe del instante; no es ley muerta, sino que está siempre brotando y confirmándose en sus propias decepciones: necesita decepciones para no enmohecerse, para no enrigidecerse en acción organizada según esquemas, y seguir manando como agua viva.

El cumplimiento en el mundo del mandamiento de Dios no es simplemente un acto aislado, sino toda una serie de actos, y un volver a empezar siempre desde el comienzo. Si no fuera así; si el acto fuera lo que engendra una dirección de la voluntad que ya existe, no sería acto de amor, sino acto ideológico. Obediencia ciega. Solo el mandamiento del amor es incapaz de convertirse en ley. No es Abraham el que no sabe amar, podría decir Rosenzweig, sino el Estado. Por eso el Estado es incapaz de convertir en ley el mandamiento, porque no puede amar. En este punto, decíamos, Rosenzweig es absolutamente concordante con el joven Hegel, que establecía el amor como ese "más" por el cual desaparece todo pensamiento de deber: no la disolución de las leyes, sino la necesidad de que las mismas se colmen con una justicia distinta. Reconciliación con el amor que se aparecía, para Hegel, como la liberación suprema, la superación de la dominación en la restauración de la unidad viviente. 
Notamos, a lo largo de este trabajo, que la diferencia entre Hegel y Rosenzweig no se da tanto, entonces, en el tratamiento de las diversas figuras de la conciencia, que de hecho son muy similares, sino en el método que se utiliza para relacionar una con otra. La crítica rosenzweigiana de Hegel no apunta tanto hacia aquello que Hegel pensó, sino a cómo lo hizo, esto es: como un progresivo desarrollo del espiritu hacia la meta de su saber absoluto. Cierto que para llegar a la meta es necesario atravesar los diversos estadios, podría decir Hegel, pero estos no dejan de ser errores que deben ser superados. Contra este tipo de pensamiento, Rosenzweig muestra, desde el comienzo de La Estrella, que no se trata de eliminar uno de los elementos por la prioridad del otro, sino de pensarlos siempre en correlación: vimos cómo Dios-Hombre-Mundo constituye una triple facticidad ineliminable y analizamos el modo por el cual el proceso de "autoconciencia" muestra su necesidad dialógica, a través del amor.

\section{Más allá de Hegel: judaísmo y cristianismo}

Hegel había AFIRMAdo que la dialéctica general de la religión constituye una revelación progresiva del espíritu en sí mismo. El primer momento de esta revelación es el de la "religión natural", en la cual el espíritu se sabe inmediatamente. Se trata del momento del Dios sustancia y no del Dios sujeto. El segundo momento, en cambio, es el de la "religión estética" griega: el espíritu ha superado la inmediatez abstracta de la naturaleza sin más, ha devenido para él mismo el sí mismo finito, el sí mismo que es una obra, pero al que le falta la profundidad del primer momento. El tercer momento, como siempre, reconcilia los anteriores: se trata de la religión revelada. Para Hegel, esta revelación solo se completa con el cristianismo, que supera las representaciones incompletas de las religiones anteriores. En el cristianismo, el espíritu absoluto se da en sí la figura de la autoconciencia, como un hombre real, lo que permite que la conciencia creyente vea y sienta y oiga esta divinidad. "La conciencia, entonces, no sale de su interior partiendo del pensamiento y no enlaza en sí el pensamiento de Dios con el ser allí, sino que parte del ser allí presente inmediato y reconoce en él a Dios" (Hegel, 2000, p. 438). Hegel considera, entonces, que la encarnación humana de la esencia divina es el contenido simple de la religión absoluta. 
Habíamos dicho que Hegel le quita protagonismo, en la Fenomenología, al tema del amor -al menos en relación con el papel preponderante que tenía en sus trabajos de juventud- pero el amor reaparece en esta instancia en la enajenación del espíritu en "el reino del Hijo":

la relación de la esencia eterna con su ser para sí es la relación inmediata y simple del puro pensamiento; en este simple intuirse de sí mismo en el ser otro no se pone, por tanto, como tal; es la diferencia tal como en el puro pensamiento no es inmediatamente diferencia alguna, un reconocimiento del amor en el que los dos no se contraponen en cuanto a su esencia (Hegel, 2000, p. 446).

En sus Escritos de juventud, como vimos, Hegel (1978) había contrapuesto el cristianismo, como religión del amor, al judaísmo, afirmando que Abraham ya no podría amar. "Vete de tu tierra, y de la casa de tus padres, hacia la tierra que yo te mostraré", le dice Dios a Abraham en la famosa parashat "Lej Lejá". Abraham, explica Hegel, corta entonces todos los vínculos naturales a partir de la llamada de una trascendencia absoluta oponiéndose, de ese modo, a la naturaleza y a la vida. Abraham abandona la relación con el mundo, se desvincula de sus parientes por un mero afán de independencia; sin ser obligado a abandonar su patria, desea hacerlo. Por eso, para Hegel, Abraham es capaz de sacrificar a su propio hijo. Porque incluso su propio hijo se le aparece como algo extraño.

Cierto que el pedido de Dios hacia Abraham es, en un primer momento, una ruptura radical de todo vínculo. Pero Hegel olvida la segunda parte del relato: Dios le promete a Abraham que hará, de él, una gran nación. Abraham no se va de su tierra por un éxtasis místico, sino por la promesa de un futuro y de su descendencia, esto es: de su realización en el mundo. En ese sentido, no es sustancialmente distinto al análisis del reino del Hijo que establece Hegel para el caso del cristianismo.

De ese modo, Rosenzweig (Rosenzweig \& Rosenstock, 2017) puede plantear que judaísmo y cristianismo mantienen una diferencia sin oposición, simbolizada en la letra "y" que une ambas religiones en una correlación complementaria: el cristianismo le recuerda al judaísmo que la redención debe darse en el mundo, mientras que el judaísmo le recuerda al cristianismo que el mundo debe ser aún redimido y que la promesa todavía no se ha cumplido: "esta es la relación de comunidad y de incomunidad (comunidad necesaria porque se alimenta de la 
misma raíz, la de la meta eterna, dependencia recíproca y por tanto separación en todo tiempo)" (p. 23).

Unos años antes de la publicación de La Estrella, en 1916, tuvo lugar uno de los debates más importantes de principios del siglo XX acerca de la relación entre judaísmo y cristianismo, cuando Rosenzweig y Rosenstock - este último también de origen judío, convertido al cristianismo- intercambian veintiún cartas dando cuenta de su diferencia confesional, aunque, al mismo tiempo, de su unidad en Adán y de la eventual complementariedad entre ambas religiones monoteístas.

En un primer momento, Rosenzweig admira la fe de Rosenstock en el Nuevo Testamento, y decide convertirse al cristianismo en la forma en que lo hicieron los primeros cristianos: no como paganos, sino como judíos. Pero, a pesar de ese primer impulso, y luego de los oficios de Yamim Noraim, Rosenzweig (2017) decide "permanecer siendo judío":

Tengo que comunicarte algo que te apenará y que, al menos en un primer momento, te resultará incomprensible: tras una larga y, creo, fundamental reflexión, he llegado a la conclusión de revocar mi decisión. Ya no me parece necesario y por tanto, en mi caso, tampoco posible. Seguiré siendo judío (Rosenzweig, 2017, p. 17).

Su teshuvá (vuelta al judaísmo) se basó en un versículo de la Biblia, pero curiosamente, del Nuevo Testamento: la afirmación de Jesús en el Evangelio de Juan: "Yo soy el camino, la verdad y la vida; nadie viene al Padre, sino por mí" (Juan 14, 6). La noción de "camino" será central para su interpretación del cristianismo en la tercera parte de La Estrella; a su vez, Rosenzweig interpreta que el "nadie viene al Padre" hace referencia al pueblo judío (no en un sentido individual, sino comunitario), que no tiene que "ir" porque ya se encuentra en él.

En su intento por conciliar ambas religiones, Rosenzweig lee el sacrificio de Moriá y el de Gólgota en la misma dirección. Contra la lectura que hace Rosenstock del sacrificio de Isaac en Gén. 22, y que vimos que realiza Hegel, Rosenzweig considera que lo que hace Abraham no es sacrificar "algo", como Agamenón, que sacrificó lo que tenía en pos de lo que quería -y que ni siquiera hizo el sacrificio, sino que solo lo entregó y permaneció allí con la cabeza tapada-. Abraham, en cambio, no sacrifica "algo", ni siquiera un niño, sino a su único hijo, por lo que es el símbolo paradigmático, no de la individualidad propia como en 
Gólgota, sino de la existencia del pueblo y de todos los futuros hijos. Por eso Isaac es devuelto: porque la promesa permanece. Nada más ocurre, no caen ciudades, no se modifica el mundo en concreto, sino que se mantiene en pie la promesa. De ese modo, mientras que Agamenón sacrifica algo, "lo que tiene", Abraham todo lo que podría ser, y Cristo todo lo que es:

Para volver sobre este punto: los dos sacrificios, el de Moriá y el de Gólgota, tienen en común, frente a todo sacrificio pagano, que por medio de ellos no se alcanza nada (puesto que se abandona lo mismo que se recobra), sino que el sacrificio mismo se convierte en lo que permanece de la fe y, de este modo, en lo que permanece, sin más. Que esto que permanece sea desigual, aquí una comunidad eterna y allí un hombre eterno, tiene consecuencias que hacen la comprensión recíproca tan difícil que cada parte, siempre, se ve tentada de arrastrar a la otra a las cercanías de aquellos que en absoluto conocen algo que permanece [...]. Somos, para vosotros, el eterno monumento admonitorio de vuestro todavia-no (porque vosotros, que vivís en una ecclesia triumphans, necesitáis de un silencioso servidor que, cada vez que creéis haber disfrutado del pan y del vino de Dios, os grite "Señor, acuérdate del final". Se trata de una paráfrasis de la narración, por parte de Heródoto, de una leyenda según la cual Darío tenía ordenado a uno de sus sirvientes que, cada vez que la mesa estuviese servida, le recordase la batalla de Sardes diciéndole al oído, por tres veces, las siguientes palabras: "Señor, acuérdate de los atenienses". (Rosenzweig, en Rosenzweig \& Rosenstock, 2017, p. 101; Heródoto, Historias, V, v.105)

En la última parte de La Estrella de la Redención, Rosenzweig vuelve a analizar minuciosamente la relación entre judaísmo y cristianismo, esta vez a propósito de su particular "temporalidad". El cristianismo es el que convierte el presente en época, haciendo que el pasado sea ahora tan solo el tiempo de "antes del nacimiento de Cristo". Todo el tiempo siguiente, desde el paso de Cristo por la tierra hasta su retorno, es ese único gran presente, pues cada uno de los puntos contenidos en ese lapso están igual de cerca del principio y del fin. El tiempo se ha convertido en un camino único; pero en un camino cuyos principio y final se hallan más allá del tiempo: en un camino, pues, eterno. Si se pregunta al río dónde está ahora, en este momento, no se encontrará respuesta alguna; pero la respuesta que él se da a sí mismo siempre es, tan solo: "estoy de camino". Se encuentra en cada momento entre el 
principio y el final de su viaje. El pasado, fijo para siempre, es todo lo que hay antes del nacimiento de Cristo. El futuro, que va viniendo tardo, pero inexorable, es el Juicio Final. En medio, como una única hora, un día único, está la era cristiana, en la que todo es centro y todo es por igual claro como el día. Los tres tiempos del tiempo se han escindido, pues, en principio eterno, centro eterno y final eterno del eterno camino a través de esta temporalidad. La propia temporalidad desaprende a confiar en sí misma y se deja imponer esta figura en la era cristiana.

Es común tanto al judaísmo (vida eterna) como al cristianismo (camino eterno) el hecho de que son eternos. No se encuentra allí para Rosenzweig la diferencia. Vida eterna y Camino eterno son cosas tan distintas como lo son la infinitud de un punto y la infinitud de una línea. La infinitud de un punto consiste en que jamás se borra: se conserva en la eterna relación del nieto con el hijo. En cambio, la infinitud de una línea termina si es que ya no es posible prolongarla. Consiste en la posibilidad de la prolongación sin trabas. El cristianismo, en tanto que camino eterno, tiene que extenderse siempre. Por eso la cristiandad debe enviar misioneros. La eternidad se vuelve eternidad del camino haciendo paulatinamente a todos los puntos del camino puntos medios.

En estas diferencias y similitudes, Rosenzweig comprende que ambas religiones son necesarias en una relación sin oposición, simbolizada en la "y": la iglesia y la sinagoga están referidas la una a la otra: la sinagoga, inmortal pero con el cetro quebrado y la venda ante los ojos, debe renunciar a todo trabajo mundano y emplear su fuerza en mantenerse con vida; la iglesia debe ocuparse del trabajo mundano y de la salvación de los gentiles.

La curva "que emerge" y la curva "que desaparece", explica Rosenzweig (1997) "para decirlo con Newton", principio y final, son los mismos para el judaísmo y para el cristianismo, la única diferencia es el punto que se elige para describir la curva. En términos éticos: el contenido de la piedad es el mismo en uno y otro caso. Tanto el judío como el cristiano se encuentran, entonces, en relación con la verdad, aunque de forma diferente: el judío está por delante, y contempla el fuego que arde en su centro, pero sin poder ver los rayos que salen de ella. El cristiano, en cambio, se encuentra de espaldas y no puede ver el fuego, pero sí los rayos que salen hacia el mundo. Por eso, ambas son parciales y complementarias entre sí. Esto no habla de una falencia en ninguna de esas religiones, sino de la conformación 
misma de la verdad: forma parte de la esencia de la verdad el hecho de aparecer partida y el hecho de ser siempre com-partida.

\section{Referencias}

Fink, E. (2011). Interpretaciones fenomenológicas de la Fenomenología del espíritu. (Trad. I. Ortega Rodríguez). Barcelona: Herder.

Gordon, P. (2003). Rosenzweig and Heidegger. Between Judaism and German Philosophy. Los Angeles: University of California Press.

Görtz, H-J. (1984). Tod und Erfahrung: Rosenzweigs „erfahrende Philosophie“ und Hegels „Wissenschaft der Erfahrung des Bewußtseins". Düsseldorf: Patmos. Hegel, W. (1978). Escritos de juventud. (Trad. Z. Szankay \& J. M. Ripalda). Ciudad de México: Fondo de Cultura Económica.

Hegel, W. (2000). Fenomenología del espiritu. (Trad. W. Roces \& R. Guerra). Ciudad de México: Fondo de Cultura Económica.

Hyppolite, J. (1974). Génesis y estructura de la Fenomenología del espíritu de Hegel. (Trad. F. Fernández Buey). Barcelona: Ediciones Península.

Mosès, S. (1982). Système et Révélation. La philosophie de Franz Rosenzweig. Paris: Éditions du Seuil.

Navarrete, R. (2016). „Der Jude, der in deutschen Geist macht." Das Hegelbuch Franz Rosenzweigs und seine Wirkung. Naharaim, 10(2), 273-302. doi: 10.1515/naha-2016-0018

Pollock, B. (2014). Franz Rosenzweig's Conversions: World Denial and World Redemption. Bloomington: Indiana University Press.

Rosenzweig, F. (1976). Der Mensch und sein Werk. Gesammelte Schriften. Den Haag: Martinus Nijhoff.

Rosenzweig, F. (1997). La Estrella de la Redención. (Trad. M. García-Baró). Salamanca: Ediciones Sígueme.

Rosenzweig, F. (2007a). Carta a Friedrich Meinecke. En: Lo bumano, lo divino y lo mundano (pp. 83-88). (Trad. M. C. Burello). Buenos Aires: Araucaria.

Rosenzweig, F. (2007b). Hegel y el Estado. En: Lo humano, lo divino y lo mundano (pp. 81-82). (Trad. M. C. Burello). Buenos Aires: Araucaria.

Rosenzweig, F. \& Rosenstock, E. (2017). Cartas sobre judaísmo y cristianismo. (Trad. R. Navarrete Alonso). Salamanca: Sígueme. 